\title{
Platelet-to-Lymphocyte Ratio and Large Tumor Size Predict Microvascular Invasion after Resection for Hepatocellular Carcinoma
}

\author{
Narongsak Rungsakulkij*, Somkit Mingphruedhi, Wikran Suragul, Pongsatorn \\ Tangtawee, Paramin Muangkaew, Suraida Aeesoa
}

\begin{abstract}
Background: Recurrence after curative resection of hepatocellular carcinoma (HCC) is associated with early death and poor prognosis. Microvascular invasion (mVI) is strongly associated with disease recurrence. Although many studies have examined the relationship between various serum inflammatory indices and post-treatment prognosis, little is known about preoperative predictors of microvascular invasion in HCC. Methods: Patients who underwent curative hepatic resection for HCC at our institute from January 2006 to December 2016 were retrospectively reviewed. The associations between $\mathrm{mVI}$ and various potential risk factors, including tumor size, hepatitis $\mathrm{B}$ and $\mathrm{C}$ virus infection, Child-Pugh scores, platelet-to-lymphocyte ratio, and neutrophil-to-lymphocyte ratio, were analyzed. Optimal cut-off values were determined using receiver operating characteristic curves. Results: A total of 330 HCC patients were enrolled in this study, of whom $74(22.4 \%)$ had tumors with $\mathrm{mVI}$. After univariate analysis, two parameters were significantly associated with $\mathrm{mVI}$ after hepatic resection: platelet-to-lymphocyte ratio $\geq 102$ (odds ratio [OR] 2.385, $\mathrm{p}=0.001)$ and tumor size $\geq 5 \mathrm{~cm}(\mathrm{OR} 4.29, \mathrm{p}<0.001)$. Both variables remained significant risk factors for $\mathrm{mVI}$ after multivariate analysis: platelet-to-lymphocyte ratio $\geq 102(\mathrm{OR} 1.831, \mathrm{p}=0.034)$ and tumor size $\geq 5 \mathrm{~cm}(\mathrm{OR} 3.791$, $p<0.001)$. Conclusions: Large tumor size $(\geq 5 \mathrm{~cm})$ and high platelet-to-lymphocyte ratio $(\geq 102)$ are independent predictive factors for $\mathrm{mVI}$ in $\mathrm{HCC}$.
\end{abstract}

Keywords: Hepatocellular carcinoma- risk factors- platelet-to-lymphocyte- prognosis- microvascular

Asian Pac J Cancer Prev, 19 (12), 3435-3441

\section{Introduction}

Hepatocellular carcinoma (HCC) is the fifth most common cancer worldwide (Torre et al., 2015). Many treatment options are available for HCC, depending on the stage of disease and the presence of liver cirrhosis (Bruix et al., 2016), but liver transplantation is considered the optimal approach because it treats both the tumor and background liver disease simultaneously. However, in Thailand, resection is the main treatment option because of the limited availability of donor organs. Although the overall morbidity and mortality associated with surgical treatment of HCC have declined in recent years, the rate of cancer recurrence remains high (Fan et al., 1999; Imamura et al., 2003; Regimbeau et al., 2004; Liu et al., 2015). Indeed, recurrent intrahepatic disease is the most common cause of death from HCC (Lim et al., 2012; Bruix et al., 2016).

Microvascular invasion (mVI), large tumor size, multifocality, high serum alpha-fetoprotein (AFP) concentration, and liver cirrhosis are among the known risk factors for poor prognosis in HCC (Poon et al., 2000b; Cha et al., 2003; Regimbeau et al., 2004; Kaibori et al., 2009; Kamiyama et al., 2012). Of these, $\mathrm{mVI}$ is the most commonly reported predictor of poor prognosis of HCC after curative resection (Poon et al., 2000a; Lim et al., 2011; Rodriguez-Peralvarez et al., 2013). The American Joint Committee on Cancer Staging manual, 7th edition (Compton Cc, 2006), classifies HCC with mVI as T2, regardless of the tumor size. A second form of vascular invasion is macrovascular (Sumie et al., 2014), which is defined as tumor growth into a major vessel that can be identified by macroscopic examination or preoperative radiological imaging. According to the Barcelona Clinic Liver Cancer Classification system, macrovascular invasion is a contraindication for liver transplantation due to very high recurrence rate (Bruix et al., 2016). In contrast, $\mathrm{mVI}$, which is defined as the presence of tumor emboli in a portal pedicle vein, a large capsule vessel, or a vascular space lined by endothelial cells, does not preclude

Department of Surgery, Faculty of Medicine, Ramathibodi Hospital, Mahidol University, Bangkok, Thailand. *For Correspondence: narongsak.run@mahidol.ac.th 
transplantation (Rodriguez-Peralvarez et al., 2013).

Various predictors of $\mathrm{mVI}$ in $\mathrm{HCC}$ have been reported, including tumor size, tumor capsule, tumor multifocality, and smooth tumor margin in computed tomography (Pawlik et al., 2005; Kim et al., 2008; Eguchi et al., 2010; Suh et al., 2012; Rodriguez-Peralvarez et al., 2013; Yamamura et al., 2014; Pote et al., 2015; Xia et al., 2015; Goh et al., 2016; Yang et al., 2017). In addition, several recent studies have identified several serum inflammatory factors associated with post-treatment prognosis of HCC, including platelet-to-lymphocyte ratio (PLR) (Tian et al., 2016; Huang et al., 2017; Yang et al., 2017), neutrophil-to-lymphocyte ratio (NLR) (Goh et al., 2016; Jin et al., 2017; Urabe et al., 2017), and prognostic nutritional index (PNI) (Chan et al., 2015; Wu et al., 2016). However, only a few studies have examined the relationship between inflammatory indices and $\mathrm{mVI}$ (Gomez et al., 2008; Chan et al., 2015; Zheng et al., 2017). The aim of this study was to identify preoperative predictors of $\mathrm{mVI}$ by evaluating the correlation between preoperative clinicopathological features, including serum inflammatory indices, and mVI.

\section{Materials and Methods}

\section{Patients and methods}

This was a retrospective study of 330 consecutive patients who underwent liver resection for pathologically proven HCC at the Department of Surgery at our hospital between January 2006 and December 2016. The Institutional Review Board of Ramathibodi Hospital approved the study.

Patient demographic and clinicopathological data collected included age, gender, indocyanine green retention value at $15 \mathrm{~min}$ (ICG-R15), AFP, alcohol consumption, and Child-Pugh score. All patients underwent preoperative cross-sectional dynamic imaging using either triple-phase computed tomography or magnetic resonance imaging. Liver biopsy was not routinely performed, except in cases with an inconclusive diagnosis after preoperative imaging. The tumor size was derived from preoperative imaging. Routine blood examinations included complete blood count, coagulogram, liver and kidney function tests, hepatitis $\mathrm{B}$ and $\mathrm{C}$ virus (HBV, $\mathrm{HCV}$ ) infection, and serum AFP concentration. A preoperative ICG-R15 was also performed. NLR was calculated as neutrophil count divided by the lymphocyte count. PLR was calculated as the platelet count divided by the lymphocyte count. PNI was calculated as ([albumin $\{\mathrm{g} / \mathrm{L}\}+0.005] \times$ [total lymphocyte count $\{/ \mu \mathrm{L}\}])$. HCC was diagnosed preoperatively based on characteristic findings on computed tomography or magnetic resonance imaging. In our center, patients are selected for curative resection based on the Makuuchi criteria (Miyagawa et al., 1995). The extent of liver resection was individualized according to the patient's liver functional reserve, which was mainly assessed using the Makuuchi criteria, including preoperative ascites volume, Child-Pugh score, ICG-R15, and, occasionally, volumetric computed tomography analysis.

Surgery was performed laparoscopically or by open laparotomy. Prophylactic antibiotics were routinely injected up to $30 \mathrm{~min}$ before skin incision. The incision type depended on the surgeon's preference. The Pringle maneuver was performed using intermittent clamping (clamp for $15 \mathrm{~min}$, de-clamp for $5 \mathrm{~min}$ ). Intraoperative ultrasound was routinely used to stage the disease and to guide parenchymal transection, which was performed using a Cavitron ultrasonic aspirator or the clamp crushing technique, depending on the surgeon's preference. Blood loss was estimated by an anesthesiologist, who also assessed the need for blood transfusion. The operative time was defined as the period from the start of incision until closure of the abdominal wound.

Pathological specimens were reviewed by a pathologist to confirm the diagnosis of HCC. Patients with combined cholangiocarcinoma, other kinds of malignancies, or with incomplete data were excluded from the study. mVI was defined as the presence of tumor cells in the microvasculature.

\section{Statistical analysis}

Categorical and numerical variables were analyzed using Pearson's $\chi^{2}$ test and the Mann-Whitney test, respectively. Univariate and multivariate analyses were conducted using the logistic regression model. Odds ratios (OR) and $95 \%$ confidence intervals (CI) were computed to assess the strength of the associations between the various factors and the outcome. A $p$ value of $<0.05$ was considered statistically significant. Analyses were performed using STATA program version 14 (StataCorp, College Station, TX, USA). The cut-off value for high and low PLR, 102, was determined by receiver operating characteristic (ROC) curve analysis.

\section{Results}

\section{Patient characteristics}

A total of 330 patients underwent curative resection for HCC from January 2006 to December 2016, of whom $74(22.4 \%)$ had mVI. For analyses, the patients were divided into $\mathrm{mVI}+(\mathrm{n}=74)$ and $\mathrm{mVI}-(\mathrm{n}=256)$ groups. The clinicopathological characteristics of the two groups are shown in Table 1. The mVI+ group had significantly higher median platelet counts than the mVI- group (2.07 $\times 105 / \mu \mathrm{L}$ [range $0.94-8.5$ ] vs $1.92 \times 105 / \mu \mathrm{L}$ [0.14-6.90], p $=0.009)$ and median PLR (129.2 vs 94.1, p=0.001). The median tumor size was also higher in the $\mathrm{mVI}+$ group than the mVI- group ( 6.8 vs $4.0 \mathrm{~cm}, \mathrm{p}<0.001)$. In the $\mathrm{mVI}+$ group $(n=74)$, there was a significant difference in the number of patients with tumor size $<5 \mathrm{~cm}$ compared with $\geq 5 \mathrm{~cm}(19 \mathrm{vs} 55, \mathrm{p}<0.001)$ and in the number of patients with PLR $<102$ compared with PLR $\geq 102$ (47 vs $27, p$ $=0.001$; Table 1). There were no significant differences between the two groups with respect to age, gender, HBV, HCV, ICG-R15, AFP, international normalized ratio (INR), NLR, PNI, alcohol consumption, Child-Pugh score, number of tumors, or multifocality.

\section{Univariate and multivariate analyses}

The results of the univariate and multivariate analyses of potential predictors of $\mathrm{mVI}$ are shown in Table 2 . 
Table 1. Preoperative Characteristics of Patients Stratified by Microvascular Invasion

\begin{tabular}{|c|c|c|c|c|}
\hline Characteristics & Total $(n=330)$ & $m V I-(n=256)$ & $\mathrm{mVI}+(\mathrm{n}=74)$ & $\mathrm{p}$ value \\
\hline Age (years), mean $\pm \mathrm{sd}^{\mathrm{a}}$ & $58.12(10.65)$ & $58.32(10.31)$ & $57.44(11.76)$ & 0.536 \\
\hline Platelets $\left(\times 10^{5} / \mu \mathrm{L}\right)$ & $1.95(0.14-8.50)$ & $1.92(0.14-6.90)$ & $2.07(0.94-8.5)$ & 0.009 \\
\hline INR (U/L) & $1.06(0.06-1.70)$ & $1.06(0.06-1.70)$ & $1.04(0.84-1.28)$ & 0.238 \\
\hline $\operatorname{AFP}(\mathrm{ng} / \mathrm{mL})$ & $15.20(0.89-82392)$ & $13.56(0.89-60500)$ & $33.5(0.9-82392)$ & 0.09 \\
\hline ICG-R15 (\%) & $14.70(0.10-51.60)$ & $14.90(0.50-51.60)$ & $13.95(0.10-33.80)$ & 0.247 \\
\hline Tumor size $(\mathrm{cm})$ & $4.5(0.1-26.5)$ & $4(0.10-19)$ & $6.80(1.50-26.50)$ & 0 \\
\hline Lymphocytes $(/ \mu \mathrm{L})$ & $1,900.8(480-21060)$ & $1,938.4(480-21060)$ & $1,803(630-4893)$ & 0.266 \\
\hline PLR & $101.7(6.89-536.83)$ & $94.1(6.9-536.8)$ & $129.2(38.6-370.5)$ & 0.001 \\
\hline Neutrophils $(/ \mu \mathrm{L})$ & $3,451(1064-11620)$ & $3,440(1064-10600)$ & $3,583(1575-11620)$ & 0.476 \\
\hline PNI & $95.37(24.4-1053.3)$ & $97.3(24.4-1053.3)$ & $90.6(31.8-245.0)$ & 0.272 \\
\hline NLR & $1.81(0.33-10.62)$ & $1.78(0.50-10.62)$ & $2.03(0.33-6.38)$ & 0.162 \\
\hline \multicolumn{5}{|l|}{ PNI, $\mathrm{n}(\%)(\mathrm{n}=312)$} \\
\hline$<95$ & $153(49.04)$ & $114(47.30)$ & $39(54.93)$ & 0.259 \\
\hline$>95$ & $159(50.96)$ & $127(52.70)$ & $32(45.07)$ & \\
\hline \multicolumn{5}{|l|}{ NLR, $n(\%)(n=310)$} \\
\hline$<1.8$ & $153(49.35)$ & $122(50.62)$ & $31(44.93)$ & 0.404 \\
\hline$>1.8$ & $157(50.65)$ & $119(49.38)$ & $38(55.07)$ & \\
\hline \multicolumn{5}{|l|}{ Tumor size, n (\%) } \\
\hline$<5 \mathrm{~cm}$ & $172(52.12)$ & $153(59.77)$ & $19(25.68)$ & 0 \\
\hline$>5 \mathrm{~cm}$ & $158(47.88)$ & $103(40.23)$ & $55(74.32)$ & \\
\hline \multicolumn{5}{|l|}{ PLR, n (\%) } \\
\hline$<102$ & $175(53.03)$ & $148(57.81)$ & $27(36.49)$ & 0.001 \\
\hline$>102$ & $155(46.97)$ & $108(42.19)$ & $47(63.51)$ & \\
\hline \multicolumn{5}{|l|}{ Gender, n (\%) } \\
\hline Male & $127(38.48)$ & $101(39.45)$ & $26(35.14)$ & 0.501 \\
\hline Female & $203(61.52)$ & $155(60.55)$ & $48(64.86)$ & \\
\hline \multicolumn{5}{|l|}{ HBV, n (\%) } \\
\hline Negative & $147(44.55)$ & $109(42.58)$ & $38(51.35)$ & 0.181 \\
\hline Positive & $183(55.45)$ & $147(57.72)$ & $36(48.65)$ & \\
\hline \multicolumn{5}{|l|}{$\mathrm{HCV}, \mathrm{n}(\%)$} \\
\hline Negative & $271(82.12)$ & $212(82.81)$ & $59(79.73)$ & 0.542 \\
\hline Positive & $59(17.88)$ & $44(17.19)$ & $15(20.27)$ & \\
\hline \multicolumn{5}{|c|}{ Alcohol consumption, $n(\%)(n=299)$} \\
\hline None & $167(55.85)$ & $132(51.56)$ & $35(47.30)$ & 0.572 \\
\hline Occasional & $70(23.41)$ & $51(19.92)$ & $19(25.68)$ & \\
\hline Alcoholism & $62(20.74)$ & $47(18.36)$ & $15(20.27)$ & \\
\hline \multicolumn{5}{|c|}{ Child-Pugh, n $(\%)(\mathrm{n}=309)$} \\
\hline A & $293(94.82)$ & $229(95.02)$ & $64(94.12)$ & 0.767 \\
\hline $\mathrm{B}$ & $16(5.18)$ & $12(4.98)$ & $4(5.88)$ & \\
\hline \multicolumn{5}{|l|}{ Multifocal tumor, n (\%) } \\
\hline Single & $255(77.27)$ & $200(78.13)$ & $55(74.32)$ & 0.492 \\
\hline Multiple & $75(22.73)$ & $56(21.88)$ & $19(25.68)$ & \\
\hline
\end{tabular}

a , Age is presented as the mean \pm standard deviation (sd). All other data are presented as the median (range) or number (\%) of patients; AFP, alpha-fetoprotein; CI, confidence interval; HCV, hepatitis C virus; ICG, indocyanine green retention; INR, international normalized ratio; mVI-/+, microvascular invasion absent/present; NLR, neutrophil-to-lymphocyte ratio; PLR, platelet-to-lymphocyte ratio; PNI prognostic nutritional index, PTT, partial thromboplastin time; sd, standard deviation.

Univariate analysis identified two variables significantly associated with $\mathrm{mVI}$ after hepatic resection: PLR $\geq 102$ (OR 2.385, $\mathrm{p}=0.001)$ and tumor size $\geq 5 \mathrm{~cm}(\mathrm{OR} 4.29$, $\mathrm{p}<0.001)$. In multivariate analysis, these variables remained significant predictive indicators of $\mathrm{mVI}$ : PLR $\geq 102(\mathrm{OR} 1.831, \mathrm{p}=0.034)$ and tumor size $\geq 5 \mathrm{~cm}(\mathrm{OR}$ $3.791, \mathrm{p}<0.001)$. 
Table 2. Univariate and Multivariate Analysis of Predictors of Microvascular Invasion

\begin{tabular}{|c|c|c|c|c|}
\hline \multirow[t]{2}{*}{ Variables } & \multicolumn{2}{|l|}{ Univariate } & \multicolumn{2}{|l|}{ Multivariate } \\
\hline & OR $(95 \% \mathrm{CI})$ & $\begin{array}{c}\mathrm{p} \\
\text { value }\end{array}$ & OR $(95 \% \mathrm{CI})$ & $\begin{array}{c}\mathrm{p} \\
\text { value }\end{array}$ \\
\hline Age (years) & $0.992(0.96-1.02)$ & 0.535 & & \\
\hline INR & $0.418(0.04-4.15)$ & 0.457 & & \\
\hline \multicolumn{5}{|c|}{$\operatorname{AFP}(<400$ ng/mL) } \\
\hline$>400 \mathrm{ng} / \mathrm{mL}$ & $1.557(0.91-2.65)$ & 0.102 & & \\
\hline \multicolumn{5}{|l|}{ PLR $(<102)$} \\
\hline$>102$ & $2.385(1.39-4.07)$ & 0.001 & $1.831(1.05-3.21)$ & 0.034 \\
\hline \multicolumn{5}{|l|}{ PNI $(<95)$} \\
\hline$>95$ & $0.736(0.43-1.25)$ & 0.259 & & \\
\hline \multicolumn{5}{|l|}{$\operatorname{NLR}(<1.8)$} \\
\hline$>1.8$ & $1.167(0.96-1.42)$ & 0.121 & & \\
\hline \multicolumn{5}{|c|}{ Tumor size $(<5 \mathrm{~cm})$} \\
\hline$>5 \mathrm{~cm}$ & $4.299(2.41-7.66)$ & 0 & $3.791(2.1-6.84)$ & 0 \\
\hline \multicolumn{5}{|l|}{ Gender (Male) } \\
\hline Female & $1.202(0.70-2.06)$ & 0.502 & & \\
\hline \multicolumn{5}{|c|}{ HBV (Negative) } \\
\hline Positive & $0.702(0.42-1.18)$ & 0.182 & & \\
\hline \multicolumn{5}{|c|}{ HCV (Negative) } \\
\hline Positive & $1.224(0.64-2.35)$ & 0.543 & & \\
\hline \multicolumn{5}{|c|}{ Alcohol (None) } \\
\hline Occasional & $1.405(0.74-2.68)$ & 0.302 & & \\
\hline Alcoholism & $1.203(0.60-2.40)$ & 0.599 & & \\
\hline \multicolumn{5}{|c|}{ Child-Pugh score (A) } \\
\hline $\mathrm{B}$ & $1.193(0.37-3.82)$ & 0.767 & & \\
\hline \multicolumn{5}{|c|}{ Multifocal tumor (Single) } \\
\hline zMultiple & $1.233(0.68-2.25)$ & 0.492 & & \\
\hline
\end{tabular}

AFP, alpha-fetoprotein; CI, confidence interval; HBV, hepatitis B virus; $\mathrm{HCV}$, hepatitis $\mathrm{C}$ virus; INR, international normalized ratio; NLR, neutrophil-to-lymphocyte ratio; OR, odds ratio; PLR, plateletto-lymphocyte ratio; PNI, prognostic nutritional index.

\section{Discussion}

The presence of $\mathrm{mVI}$ is strongly associated with $\mathrm{HCC}$ recurrence and early disease-related death (Poon et al., 2000a; Poon et al., 2007; Lim et al., 2011). Several studies have shown that $\mathrm{mVI}+$ patients have poorer prognosis than $\mathrm{mVI}-$ patients (Pawlik et al., 2005; Yamamoto et al., 2015; Hirokawa et al., 2016; Shimoda et al., 2016). Although there is currently no consensus definition of mVI, Rodriguez-Peralvarez (2013) recently proposed the following criteria: (i) the presence of tumor cells forming plug or polyp and (ii) tumor thrombus partially or totally covered by endothelial cells in either the portal vein or hepatic vein branches. They also suggested that tumor cells or small clusters of tumor cells freefloating inside isolated vessels but not covered by endothelium should not be considered part of the criteria (Rodriguez-Peralvarez et al., 2013). In the present study, we defined $\mathrm{mVI}$ according to these criteria. The rate of $\mathrm{mVI}$ in this study was $22.4 \%$, comparable to that seen in previous studies (Kim et al., 2008; Eguchi et al., 2010; Rodriguez-Peralvarez et al., 2013; Shimoda et al., 2016). Since mVI cannot be identified preoperatively, knowledge
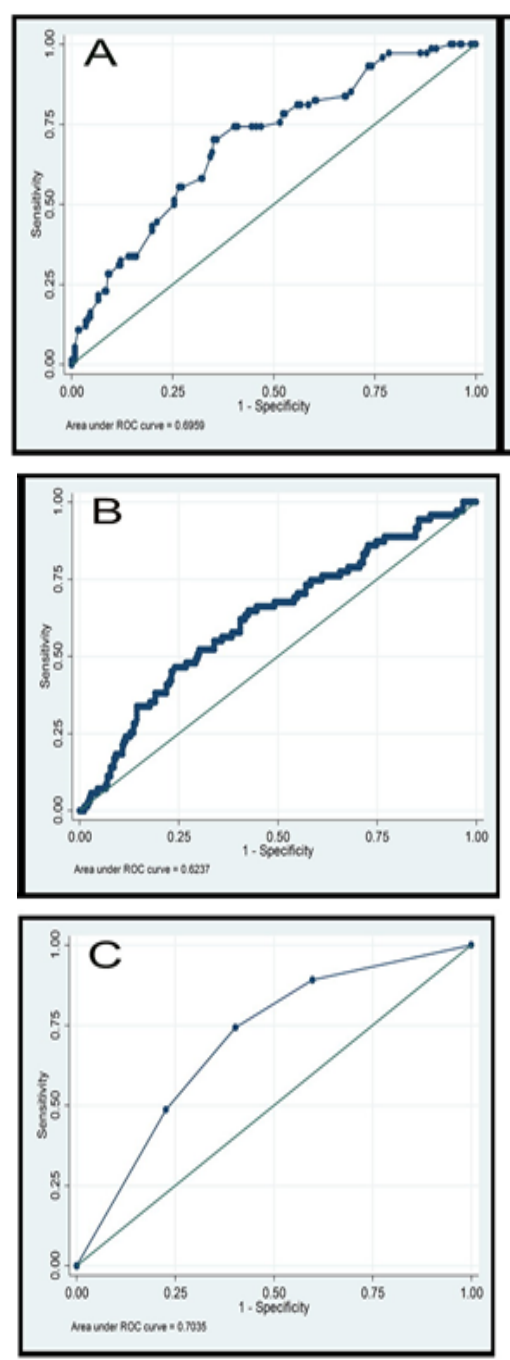

Figure 1. Receiver Operating Characteristic Curves for Predicting Microvascular Invasion. (A) Tumor size. (B) Platelet-to-lymphocyte ratio. (C) Tumor size $\geq 5 \mathrm{~cm}$ and platelet-to-lymphocyte ratio $\geq 102$.

of significant risk factors could be of great help to the surgeon for preoperative preparation. From univariate and multivariate analyses, we identified tumor size $\geq 5 \mathrm{~cm}$ and PLR $\geq 102$ as preoperative predictors of $\mathrm{mVI}$.

Angiogenesis is the main mechanism of $\mathrm{mVI}$ in $\mathrm{HCC}$. Rodriguez-Peralvarez (2013) reported that vascular invasion results when tumor cells develop a sufficiently evolved phenotype to invade blood vessels and potentially begin to metastasis. The production of proteases and reduced expression of E-cadherin result in loss of tissue integrity and further facilitate tumor invasion (Wu et al., 2011; Rodriguez-Peralvarez et al., 2013). Pawlik (2005) reported that the incidence of $\mathrm{mVI}$ positively correlated with increasing tumor size, and that $\mathrm{mVI}$ was twice as common in patients with tumors $\geq 5 \mathrm{~cm} \mathrm{vs}<5 \mathrm{~cm}$.

Although it is well-established that tumor size is associated with the outcome after resection in HCC (Shirabe et al., 2014; Hwang et al., 2015; Lei et al., 2016) and that large tumor size is associated with $\mathrm{mVI}$, there is some controversy about the optimal tumor size for risk stratification (Pawlik et al., 2005; Shindoh et al., 2013). In the present study, we identified a cut-off value of $5 \mathrm{~cm}$ 
for predicting $\mathrm{mVI}$. Chen et al. reported that patients with smaller HCC tumors $(<5 \mathrm{~cm})$ have better prognosis (Chen et al., 2011). In addition, several large population studies in HCC have identified a relationship between $\mathrm{mVI}$ and $>5 \mathrm{~cm}$ tumors (Pawlik et al., 2005; Kaibori et al., 2009; Huang et al., 2015; Hwang et al., 2015). In the Barcelona Clinic Liver Cancer staging system, patients with tumor sizes $<5 \mathrm{~cm}$ are classified as having early stage $\mathrm{HCC}$ (Bruix et al., 2016). A single tumor of size $\leq 5 \mathrm{~cm}$ is one of the Milan criteria for liver transplantation (Mazzaferro et al., 2008). In accordance with these findings, we suggest a cut-off value of $5 \mathrm{~cm}$ for the association between tumor size and $\mathrm{mVI}$.

Systemic inflammatory responses play critical roles in the pathogenesis and progression of cancer (Grivennikov et al., 2010). Inflammation promotes tumor angiogenesis, invasion, and metastasis through regulation of a subset of regulatory T lymphocytes and chemokines (Mantovani et al., 2008; Fan et al., 2015). Recently, Zhou and Templeton (Templeton et al., 2014; Zhou et al., 2014) reported that PLR is a significant biomarker of poor prognosis for many cancers, including HCC. Moreover, in patients who underwent hepatic resection, transplantation, and transarterial chemoembolization, high PLR levels were associated with poor prognosis and disease recurrence (Suh et al., 2012; Xue et al., 2015; Goh et al., 2016; Song et al., 2016; Yang et al., 2017).

Few studies have investigated the relationship between PLR and mVI (Ma et al., 2016; Zheng et al., 2017). Ma (2016) performed a meta-analysis of the prognostic value of PLR in HCC and found no association with vascular invasion; however, this conclusion was based on only three eligible studies, and vascular invasion was defined as including both macrovascular invasion and mVI. The Memorial Sloan Kettering Center group (Zheng et al., 2017) investigated the utility of serum inflammatory markers as predictors of $\mathrm{mVI}$. They found that the mVI+ group had higher mean PLR values than the $\mathrm{mVI}-$, but univariate and multivariate analyses identified significant associations between $\mathrm{mVI}$ and AFP, albumin, and radiologic tumor size, but not PLR. In contrast, PLR was significantly higher in the $\mathrm{mVI}+$ group than $\mathrm{mVI}-$ group in our study, and univariate and multivariate analysis demonstrated that PLR $>102$ was an independent prognostic factor for $\mathrm{mVI}$. These apparently discrepant results could be due to the higher proportion of $\mathrm{HBV}$-infected patients (55.5\% vs $25 \%)$ and alcoholic patients $(44.3 \%$ vs $11 \%)$ in our study vs the Memorial Sloan Kettering Center study (Zheng et al., 2017). Inflammation plays a role in the severity of chronic HBV infection through antigen-nonspecific inflammatory cell enhancement of cytotoxic T lymphocyte-mediated liver damage, and platelets facilitate intrahepatic accumulation of cytotoxic T lymphocytes (Iannacone et al., 2005; Seki and Schwabe, 2015). In two studies examining inflammatory indices in patients with chronic HBV infection, Zhao and Wang (Wang et al., 2015; Zhao et al., 2017 ) both reported an association between PLR and liver fibrosis and disease severity.

Although the relationship between PLR and $\mathrm{mVI}$ has previously been investigated, no consensus cut-off value was obtained (Yamamura et al., 2014; Spolverato et al., 2015; Goh et al., 2016; Ma et al., 2016; Yang et al., 2017). Our finding that PLR $>102$ is an independent risk factor for $\mathrm{mVI}$ is consistent with previous studies, most of which identified PLR cut-off values of $>100$ (Ma et al., 2016). Notably, we showed that the combination of tumor size $\geq 5 \mathrm{~cm}$ and PLR $\geq 102$ had superior predictive sensitivity and specificity compared with either measure (Figure 1).

This study has some limitations. First, because of its retrospective nature, the study design could have some selection bias. Second, some preoperative inflammatory indices, such as the Glasgow Prognostic Score, could not be included because our center does not routinely measure C-reactive protein, which is a component of the Glasgow Prognostic Score.

In conclusions in this study, we demonstrated that large tumor size and high PLR are independent predictive risk factors for $\mathrm{mVI}$. The suggested cut-off values are $>5 \mathrm{~cm}$ for tumor size and 102 for PLR. When used in combination, these factors showed better discriminatory performance than either measure alone for predicting $\mathrm{mVI}$. These findings may be helpful for surgeons in preoperative counselling for the patients undergoing $\mathrm{HCC}$ resection.

\section{Author contributions}

NR: study design, data collection and interpretation, writing and drafting of the manuscript; SM: data collection and analysis; PT: data collection and analysis; PM: data collection; WS: data collection; SA: data collection and analysis.

\section{Fundings statement}

The authors report no funding in this work.

\section{Acknowledgments}

We thank Napaphat Proprom for help with the statistical analysis and Anne M. O'Rourke, $\mathrm{PhD}$, from Edanz Group (www.edanzediting.com/ac) for editing a draft of this manuscript.

\section{References}

Bruix J, Reig M, Sherman M (2016). Evidence-based diagnosis, staging, and treatment of patients with hepatocellular carcinoma. Gastroenterology, 150, 835-53.

Cha C, Fong Y, Jarnagin WR, et al (2003). Predictors and patterns of recurrence after resection of hepatocellular carcinoma. $J$ Am Coll Surg, 197, 753-8.

Chan AW, Chan SL, Wong GL, et al (2015). Prognostic nutritional index (PNI) predicts tumor recurrence of very early/early stage hepatocellular carcinoma after surgical resection. Ann Surg Oncol, 22, 4138-48.

Chen YL, Ko CJ, Chien SY, et al (2011). Tumor size as a prognostic factor in resected small hepatocellular carcinoma: a controversy revisited. J Gastroenterol Hepatol, 26, 851-7.

Compton CC, Garcia-Aguilar J, Kurtzman SH, Olawaiye A, Washington MK (2006). AJCC cancer staging atlas: A companion to the seventh editions of the AJCC cancer staging manual and handbook, New York, Springer, pp 241-9.

Eguchi S, Takatsuki M, Hidaka M, et al (2010). Predictor for histological microvascular invasion of hepatocellular

Asian Pacific Journal of Cancer Prevention, Vol 19 
carcinoma: A lesson from 229 consecutive cases of curative liver resection. World J Surg, 34, 1034-8.

Fan ST, Lo CM, Liu CL, et al (1999). Hepatectomy for hepatocellular carcinoma: toward zero hospital deaths. Ann Surg, 229, 322-30.

Fan W, Zhang Y, Wang Y, et al (2015). Neutrophil-to-lymphocyte and platelet-to-lymphocyte ratios as predictors of survival and metastasis for recurrent hepatocellular carcinoma after transarterial chemoembolization. PLoS One, 10, e0119312.

Goh BK, Kam JH, Lee SY, et al (2016). Significance of neutrophil-to-lymphocyte ratio, platelet-to-lymphocyte ratio and prognostic nutrition index as preoperative predictors of early mortality after liver resection for huge $(>/=10 \mathrm{~cm})$ hepatocellular carcinoma. J Surg Oncol, 113, 621-7.

Gomez D, Farid S, Malik HZ, et al (2008). Preoperative neutrophil-to-lymphocyte ratio as a prognostic predictor after curative resection for hepatocellular carcinoma. World J Surg, 32, 1757-62.

Grivennikov SI, Greten FR, Karin M (2010). Immunity, inflammation, and cancer. Cell, 140, 883-99.

Hirokawa F, Hayashi M, Asakuma M, et al (2016). Risk factors and patterns of early recurrence after curative hepatectomy for hepatocellular carcinoma. Surg Oncol, 25, 24-9.

Huang GQ, Zheng JN, Zou TT, et al (2017). Stratified platelet-to-lymphocyte ratio: A novel target for prognostic prediction of hepatocellular carcinoma after curative liver resection. J Clin Transl Hepatol, 5, 35-42.

Huang WJ, Jeng YM, Lai HS, et al (2015). Tumor size is a major determinant of prognosis of resected stage I hepatocellular carcinoma. Langenbecks Arch Surg, 400, 725-34.

Hwang S, Lee YJ, Kim KH, et al (2015). The impact of tumor size on long-term survival outcomes after resection of solitary hepatocellular carcinoma: Single-institution experience with 2558 patients. $J$ Gastrointest Surg, 19, 1281-90.

Iannacone M, Sitia G, Isogawa M, et al (2005). Platelets mediate cytotoxic T lymphocyte-induced liver damage. Nat Med, 11, 1167-9.

Imamura H, Seyama Y, Kokudo N, et al (2003). One thousand fifty-six hepatectomies without mortality in 8 years. Arch Surg, 138, 1198-206; discussion 206.

Jin C, Li C, Peng W, et al (2017). Changes of platelet times neutrophil to lymphocyte ratio predict BCLC stage A hepatocellular carcinoma survival. Medicine (Baltimore), 96, e7821.

Kaibori M, Ishizaki M, Saito T, et al (2009). Risk factors and outcome of early recurrence after resection of small hepatocellular carcinomas. Am J Surg, 198, 39-45.

Kamiyama T, Nakanishi K, Yokoo H, et al (2012). Analysis of the risk factors for early death due to disease recurrence or progression within 1 year after hepatectomy in patients with hepatocellular carcinoma. World J Surg Oncol, 10, 107.

Kim BK, Han KH, Park YN, et al (2008). Prediction of microvascular invasion before curative resection of hepatocellular carcinoma. J Surg Oncol, 97, 246-52.

Lei Z, Li J, Wu D, et al (2016). Nomogram for preoperative estimation of microvascular invasion risk in hepatitis B virus-related hepatocellular carcinoma within the Milan criteria. JAMA Surg, 151, 356-63.

Lim KC, Chow PK, Allen JC, et al (2011). Microvascular invasion is a better predictor of tumor recurrence and overall survival following surgical resection for hepatocellular carcinoma compared to the Milan criteria. Ann Surg, 254, 108-13.

Lim KC, Chow PK, Allen JC, et al (2012). Systematic review of outcomes of liver resection for early hepatocellular carcinoma within the Milan criteria. Br J Surg, 99, 1622-9.

Liu W, Zhou JG, Sun Y, et al (2015). Hepatic resection improved the long-term survival of patients with BCLC stage B hepatocellular carcinoma in Asia: a systematic review and meta-analysis. $J$ Gastrointest Surg, 19, 1271-80.

Ma W, Zhang P, Qi J, et al (2016). Prognostic value of platelet to lymphocyte ratio in hepatocellular carcinoma: a metaanalysis. Sci Rep, 6, 35378.

Mantovani A, Allavena P, Sica A, et al (2008). Cancer-related inflammation. Nature, 454, 436-44.

Mazzaferro V, Chun YS, Poon RT, et al (2008). Liver transplantation for hepatocellular carcinoma. Ann Surg Oncol, 15, 1001-7.

Miyagawa S, Makuuchi M, Kawasaki S, et al (1995). Criteria for safe hepatic resection. Am J Surg, 169, 589-94.

Pawlik TM, Delman KA, Vauthey JN, et al (2005). Tumor size predicts vascular invasion and histologic grade: Implications for selection of surgical treatment for hepatocellular carcinoma. Liver Transpl, 11, 1086-92.

Poon RT, Fan ST, Lo CM, et al (2007). Difference in tumor invasiveness in cirrhotic patients with hepatocellular carcinoma fulfilling the Milan criteria treated by resection and transplantation: impact on long-term survival. Ann Surg, 245, 51-8.

Poon RT, Fan ST, Ng IO, et al (2000a). Different risk factors and prognosis for early and late intrahepatic recurrence after resection of hepatocellular carcinoma. Cancer, 89, 500-7.

Poon RTP, Fan ST, Wong J (2000b). Risk factors, prevention, and management of postoperative recurrence after resection of hepatocellular carcinoma. Ann Surg, 232, 10-24.

Pote N, Cauchy F, Albuquerque M, et al (2015). Performance of PIVKA-II for early hepatocellular carcinoma diagnosis and prediction of microvascular invasion. J Hepatol, 62, 848-54.

Regimbeau JM, Abdalla EK, Vauthey JN, et al (2004). Risk factors for early death due to recurrence after liver resection for hepatocellular carcinoma: Results of a multicenter study. J Surg Oncol, 85, 36-41.

Rodriguez-Peralvarez M, Luong TV, Andreana L, et al (2013). A systematic review of microvascular invasion in hepatocellular carcinoma: diagnostic and prognostic variability. Ann Surg Oncol, 20, 325-39.

Seki E, Schwabe RF (2015). Hepatic inflammation and fibrosis: functional links and key pathways. Hepatology, 61, 1066-79.

Shimoda M, Tago K, Shiraki T, et al (2016). Risk factors for early recurrence of single lesion hepatocellular carcinoma after curative resection. World J Surg, 40, 2466-71.

Shindoh J, Andreou A, Aloia TA, et al (2013). Microvascular invasion does not predict long-term survival in hepatocellular carcinoma up to $2 \mathrm{~cm}$ : reappraisal of the staging system for solitary tumors. Ann Surg Oncol, 20, 1223-9.

Shirabe K, Toshima T, Kimura K, et al (2014). New scoring system for prediction of microvascular invasion in patients with hepatocellular carcinoma. Liver Int, 34, 937-41.

Song W, Wang K, Zhong FP, et al (2016). Clinicopathological and prognostic significance of platelet-to-lymphocyte ratio in patients with hepatocellular carcinoma. Oncotarget, 7, 81830-8.

Spolverato G, Maqsood H, Kim Y, et al (2015). Neutrophillymphocyte and platelet-lymphocyte ratio in patients after resection for hepato-pancreatico-biliary malignancies. J Surg Oncol, 111, 868-74.

Suh YJ, Kim MJ, Choi JY, et al (2012). Preoperative prediction of the microvascular invasion of hepatocellular carcinoma with diffusion-weighted imaging. Liver Transpl, 18, 1171-8.

Sumie S, Nakashima O, Okuda K, et al (2014). The significance of classifying microvascular invasion in patients with hepatocellular carcinoma. Ann Surg Oncol, 21, 1002-9.

Templeton AJ, Ace O, McNamara MG, et al (2014). Prognostic role of platelet to lymphocyte ratio in solid tumors: a 
systematic review and meta-analysis. Cancer Epidemiol Biomarkers Prev, 23, 1204-12.

Tian XC, Liu XL, Zeng FR, et al (2016). Platelet-to-lymphocyte ratio acts as an independent risk factor for patients with hepatitis B virus-related hepatocellular carcinoma who received transarterial chemoembolization. Eur Rev Med Pharmacol Sci, 20, 2302-9.

Torre LA, Bray F, Siegel RL, et al (2015). Global cancer statistics, 2012. CA Cancer J Clin, 65, 87-108.

Urabe M, Yamashita H, Watanabe T, et al (2018). Comparison of prognostic abilities among preoperative laboratory data indices in patients with resectable gastric and esophagogastric junction adenocarcinoma. World J Surg, 42, 185-94.

Wang Q, Blank S, Fiel MI, et al (2015). The severity of liver fibrosis influences the prognostic value of inflammation-based scores in hepatitis B-associated hepatocellular carcinoma. Ann Surg Oncol, 22, 1125-32.

Wu SJ, Lin YX, Ye H, et al (2016). Lymphocyte to monocyte ratio and prognostic nutritional index predict survival outcomes of hepatitis B virus-associated hepatocellular carcinoma patients after curative hepatectomy. J Surg Oncol, 114, 202-10.

Wu SM, Huang YH, Yeh CT, et al (2011). Cathepsin H regulated by the thyroid hormone receptors associate with tumor invasion in human hepatoma cells. Oncogene, 30, 2057-69.

Xia W, Ke Q, Wang Y, et al (2015). Predictive value of pre-transplant platelet to lymphocyte ratio for hepatocellular carcinoma recurrence after liver transplantation. World $J$ Surg Oncol, 13, 60.

Xue TC, Jia QA, Ge NL, et al (2015). The platelet-to-lymphocyte ratio predicts poor survival in patients with huge hepatocellular carcinoma that received transarterial chemoembolization. Tumour Biol, 36, 6045-51.

Yamamoto Y, Ikoma H, Morimura R, et al (2015). Optimal duration of the early and late recurrence of hepatocellular carcinoma after hepatectomy. World J Gastroenterol, 21, 1207-15.

Yamamura K, Sugimoto H, Kanda M, et al (2014). Comparison of inflammation-based prognostic scores as predictors of tumor recurrence in patients with hepatocellular carcinoma after curative resection. J Hepatobiliary Pancreat Sci, 21, 682-8.

Yang HJ, Jiang JH, Liu QA, et al (2017). Preoperative platelet-to-lymphocyte ratio is a valuable prognostic biomarker in patients with hepatocellular carcinoma undergoing curative liver resection. Tumour Biol, 39, 1-8.

Zhao Z, Liu J, Wang J, et al (2017). Platelet-to-lymphocyte ratio (PLR) and neutrophil-to-lymphocyte ratio (NLR) are associated with chronic hepatitis B virus (HBV) infection. Int Immunopharmacol, 51, 1-8.

Zheng J, Seier K, Gonen M, et al (2017). Utility of serum inflammatory markers for predicting microvascular invasion and survival for patients with hepatocellular carcinoma. Ann Surg Oncol, 24, 3706-37.

Zhou X, Du Y, Huang Z, et al (2014). Prognostic value of PLR in various cancers: a meta-analysis. PLoS One, 9, e101119.

\section{c) (7) (8)}

This work is licensed under a Creative Commons AttributionNon Commercial 4.0 International License. 